\title{
Single and joint effect of the basal region of chromosome 2 and centromeric region of chromosome 8 on morphological and fruit quality traits in tomato
}

\author{
Gisela Yael Green · Javier Hernán Pereira da Costa • Vladimir Cambiaso • \\ Guillermo Raúl Pratta · Roxana Zorzoli · Gustavo Rubén Rodríguez
}

Received: 17 November 2015/Accepted: 31 March 2016/Published online: 11 May 2016

(C) Springer Science+Business Media Dordrecht 2016

\begin{abstract}
The goal of this study was to estimate the single and joint effect of the basal region of chromosome 2 and centromeric region of chromosome 8 on morphological and fruit quality traits in tomato (Solanum lycopersicum). The analysis was performed in a population derived from a cross between Rio Grande of S. lycopersicum and LA1589 of $S$. pimpinellifolium that segregates for both genomic regions. Four major QTLs were found on chromosome 2 and three on chromosome 8 , all of them related with morphological traits. QTLs for fruit shape index, proximal fruit end angle and distal fruit end protrusion showed epistatic interaction. Both genomic regions ( $f s 2.1$ and $f s 8.1$ ) explained 62,47 and $46 \%$ of the phenotypic variability for fruit shape index, proximal
\end{abstract}

Electronic supplementary material The online version of this article (doi:10.1007/s10681-016-1689-z) contains supplementary material, which is available to authorized users.

G. Y. Green - J. H. Pereira da Costa .

V. Cambiaso - G. R. Pratta - G. R. Rodríguez $(\square)$

IICAR (Instituto de Investigaciones en Ciencias Agrarias

de Rosario) - CONICET (Consejo Nacional de

Investigaciones Científicas y Técnicas). Cátedra de

Genética, Facultad de Ciencias Agrarias, Universidad

Nacional de Rosario, Campo Experimental Villarino CC

14 (S2125ZAA), Rosario, Argentina

e-mail: grodrig@unr.edu.ar

R. Zorzoli

IICAR-CONICET. CIUNR. Cátedra de Genética,

Facultad de Ciencias Agrarias, Universidad Nacional de

Rosario, CC 14 (S2125ZAA), Rosario, Argentina fruit end angle and distal fruit end protrusion respectively. Minor QTLs were detected for other morphological and quality traits such as color, $\mathrm{pH}$ and fruit shelf life on chromosomes 2 and 8. Only single genomic region effects were found for quality trait. On the other hand, $f s 2.1$ and $f s 8.1$ regions control several fruit morphology attributes following a digenic linear additive model with epistatic interactions.

Keywords Epistasis - Fruit color · Fruit shape · $f s 2.1 \cdot f_{s} 8.1 \cdot$ Titratable acidity

$\begin{array}{ll}\text { Abbreviations } \\ a / b & \text { Color chroma index } \\ \text { ANOVA } & \text { Analysis of variance } \\ a r & \text { Fruit area } \\ \mathrm{BC}_{1} & \text { First cycle of backcross } \\ \text { CAPS } & \text { Cleaved amplified polymorphic sequences } \\ d a n 20 & \text { Distal fruit end angle } \\ d b l k 20 & \text { Distal fruit end blockiness } \\ f & \text { Firmness } \\ \mathrm{F}_{3} & \text { Third filial generation } \\ f_{S} I & \text { Fruit shape index } \\ f w & \text { Fruit mass } \\ \mathrm{H}^{2} & \text { Broad sense heritability } \\ \text { InDel } & \text { Insertion/deletion } \\ L & \text { Lightness color parameter } \\ \text { LL } & \text { Homozygous for Rio Grande alleles } \\ \text { LP } & \text { Heterozygous } \\ \text { pan20 } & \text { Proximal fruit end angle }\end{array}$




$\begin{array}{ll}\text { pblk20 } & \text { Proximal fruit end blockiness } \\ p H & \text { Hydrogen potential } \\ \mathrm{PP} & \text { Homozygous for LA1589 alleles } \\ \text { QTL } & \text { Quantitative trait loci } \\ \mathrm{S}_{1} & \text { First selfed generation } \\ s l & \text { Fruit shelf life } \\ s s c & \text { Soluble solid content } \\ t a & \text { Titratable acidity } \\ \text { tip } & \text { Distal fruit end protrusion } \\ \text { tri20 } & \text { Fruit shape triangle }\end{array}$

\section{Introduction}

Fruit shape in tomato defines the destination of the production and is recognized as being the second most important attribute for consumers after price (Simonne et al. 2006). Elongated tomatoes are usually used in processed or manufactured products while rounded fruits are most frequently used for fresh consumption. A large diversity of shapes are present in the cultivated tomato (Solanum lycopersicum) in contrast to wild genotypes which produce spherical and small-size fruits (Rodríguez et al. 2011). Four major QTLs have been associated with elongated fruits within the cultivated tomato germplasm: ovate, sun, $f_{s} 8.1$ and $f s 2.1$ (Gonzalo and van der Knaap 2008). The SUN and OVATE genes have been cloned by positional mapping (Liu et al. 2002; Xiao et al. 2008) while the existence of the other two loci is known through mapping studies. Less than 10 loci, located in 7 of the 12 chromosomes, have been associated with most of the changes in the size and shape of tomato fruit (Tanksley 2004).

Fruit shape index ( $f_{s} I$, ratio of maximum height to maximum width) is an easy-measurement morphological character to differentiate some cultivars (Grandillo et al. 1999). The Rio Grande cultivar of $S$. lycopersicum carries the wild alleles at $S U N$ and OVATE genes (Rodríguez et al. 2011) and the $f s$ $I$ morphological parameter is controlled by $f s 8.1$ and $f s 2.1$ (Gonzalo and van der Knaap 2008). Both $f s 2.1$ and $f_{s} 8.1$ explained the 19.00 and $29.00 \%$ respectively of the phenotypic variability of $f_{s} I$ in a $\mathrm{F}_{2}$ population derived from a cross between Rio Grande and LA1589 of S. pimpinellifolium (Gonzalo and van der Knaap 2008). $f_{s} 8.1$ is located close to the centromeric region of chromosome 8 and has been mapped in a region of $3.03 \mathrm{Mb}$ (Sun et al. 2015). fs8.1 exert their effect on fruit shape at least 6 days before anthesis, probably affecting fruit growth only in the longitudinal dimension ( $\mathrm{Ku}$ et al. 2000). $f_{s} 2.1$ is located in the distal region of chromosome 2 which shows a high-recombination frequency (Grandillo and Tanksley 1996; Lippman and Tanksley 2001). $f_{s} 2.1$ and $f s 8.1$ were also detected in a backcross population derived from M82-1-7 of S. lycopersicum and LA1589 of $S$. pimpinellifolium. In that cross $f s 8.1$ explained the $27.40 \%$ and $f s .15 .70 \%$ of the phenotypic variability for the trait (Grandillo and Tanksley 1996).

Several QTLs associated with fruit quality and yield traits have been identified in the same genomic regions that control fruit shape in Rio Grande ( $f_{s} 8.1$ and $f s 2.1$ ). For example, the $f s 8.1$ region affects the number of flowers and fruits per inflorescence and the harvest index. These result suggest pleiotropic effects on these floral traits or may be that these traits could be affected by closely-linked genes (Ku et al. 2000). This same region has been associated with other traits such as fruit shelf life (Pereira da Costa et al. 2013), pericarp thickness (Grandillo and Tanksley 1996), carotene content and volatile compounds (SalibaColombani et al. 2001).

The FW2.2 gene which controls fruit weight is located in the basal region of chromosome 2 (Frary et al. 2000). Also in this region, QTLs for fruit firmness, $p H$, soluble solid content (Bernacchi et al. 1998), $L, a$ and $b$ indexes of color, titratable acidity, sugar content, carotene content, volatile compounds (Saliba-Colombani et al. 2001) and pericarp thickness (Grandillo and Tanksley 1996) have been detected.

The goal of this work was to analyze the single and joint effect of genomic regions containing $f_{s} 2.1$ and $f_{S 8.1}$ QTLs on morphological and fruit quality traits in a population derived from the cross between Rio Grande of $S$. lycopersicum and LA1589 of $S$. pimpinellifolium.

\section{Materials and methods}

Plant material

The commercial cultivar Rio Grande of S. lycopersicum and the wild accession LA1589 of S. pimpinellifolium were used as parental genotypes. The cultivated genotype has a large elongated fruit usually used for fresh 
consumption and processed products and was obtained in a tomato-breeding program in the United States of America (http://www.solgenomics.net). The wild genotype, LA1589 has small rounded fruits and is originally from Peru (http://www.solgenomics.net). The molecular characterization of the $\mathrm{F}_{2}$ population conducted by Gonzalo and van der Knaap (2008) allowed selecting that plant with higher proportion of cultivated tomato alleles covering the genome and as heterozygosity genotype in the regions spanning both the $f$ s.2.1 and $f_{s} 8.1$ loci. Using markers Lewus, TG337 and EP170/EP171 at chromosome 2 and TG176, TG45 and EP912/EP913 at chromosome 8 (Table 1), only one $\mathrm{F}_{3}$ plant heterozygous at both genomic regions were backrossed to Rio Grande as the recurrent parent. Backcross and selfing cycles were done using forward (markers shown in Table 1) and background markers (along the genome) to obtain a $\mathrm{F}_{3}-\mathrm{BC}_{1}-\mathrm{S}_{1}$ population segregating for distal end of chromosome 2 and centromeric region at chromosome 8 .

Ten plants of each parental genotype and 128 plants of a segregating population $\mathrm{F}_{3}-\mathrm{BC}_{1}-\mathrm{S}_{1}$ were transplanted into greenhouse at a distance of $1 \mathrm{~m}$ between rows and $40 \mathrm{~cm}$ between plants. Tomato plants were stringed vertically from a top-wire.

Phenotypic analysis

Six fruits from different trusses of each plant were longitudinally cut through the center, placed cut side- down on a scanner and scanned at 300 dots per inch (dpi). The fruit images were saved as jpeg files and imported into Tomato Analyzer 3.0 for automated phenotypic measurements (Rodríguez et al. 2010a). The analyzed attributes of each fruit were: fruit area $\left(a r\right.$, in $\mathrm{cm}^{2}$ ), fruit shape index ( $f s I$, ratio of maximum height to maximum width), proximal fruit end blockiness (pblk20, ratio of the width at $20 \%$ of the perimeter from the proximal end to width mid-height), distal fruit end blockiness ( $d b l k 20$, ratio of the width at $20 \%$ of the perimeter from the distal end to width mid-height), fruit shape triangle (tri20, ratio between proximal width and distal width both taken at $20 \%$ of the perimeter from the proximal and distal end respectively), proximal fruit end angle (pan20, the angle between best-fit lines drawn at $20 \%$ of the perimeter from the proximal end at both sides), distal fruit end angle (dan20, the angle between best-fit lines drawn at $20 \%$ of the perimeter from the distal end at both sides) and the distal fruit end protrusion (tip, ratio of the area of the distal protrusion to the total area of the fruit, multiplied by 10).

Seven fruits per plant were harvested to assess fruit mass ( $f w$, in grams) and shelf life ( $s l$, in days). The $s l$ trait was evaluated as the elapsed days between the harvest and the discard of the fruit. The harvested fruits were stored at $25 \pm 3{ }^{\circ} \mathrm{C}$ on a shelf and were examined three times a week discarding those commercially unacceptable (Buescher et al. 1976; Schuelter et al. 2002). Another six fruit per plant were used to

Table 1 Molecular markers' description

\begin{tabular}{|c|c|c|c|c|c|c|c|}
\hline Type & Name & Chr & Enzyme & RG allele (bp) & LA allele (bp) & Primer & Sequence $5^{\prime} \rightarrow 3^{\prime}$ \\
\hline \multirow[t]{6}{*}{ InDel } & Lewus & 2 & - & 210 & 222 & Forward & TGGAACTTTGGCTATGGAGAA \\
\hline & & & & & & Reverse & TGGTGAAGAAAATGTTGTTTTGAT \\
\hline & EP170/EP171 & 2 & - & 169 & 179 & Forward & CACATCTTACGATTATTGGGGTAA \\
\hline & & & & & & Reverse & TGTGCACACATCTTAACAAATCA \\
\hline & EP912/EP913 & 8 & - & 180 & 195 & Forward & TGATGTCACTGGGCATCTTC \\
\hline & & & & & & Reverse & GACAAATTCCTGAGCTTACTGC \\
\hline \multirow[t]{6}{*}{ CAPS } & TG337 & 2 & Hind III & 1500 & $1000 / 500$ & Forward & GCAAAGCATCATCACCAATG \\
\hline & & & & & & Reverse & ATTATGGGCCACACGCAATA \\
\hline & TG176 & 8 & Rsa I & 234 & 325 & Forward & AGTAATAGCACTGCCCCACA \\
\hline & & & & & & Reverse & TTCGGCAAGTTTAGCCAAATA \\
\hline & TG45 & 8 & Dde I & 98 & 78 & Forward & AGCGGAACTTGTCATCCATC \\
\hline & & & & & & Reverse & TGAGTGGCCATTTTTAAATGCCTC \\
\hline
\end{tabular}

Chr chromosome, InDel insertion/deletion, CAPS cleaved amplified polymorphic sequence, RG Rio Grande of S. lycopersicum, LA LA1589 of S. pimpinellifolium 
assess firmness $(f)$ measured on the equatorial plane in two opposite areas of each fruit with a $0.10 \mathrm{~cm}^{2}$ tip durometer (Durofel DFT100). Color was measured as the percentage of reflectance $(L)$ and the chroma index $(a / b)$ using a CR300 colorimeter. Soluble solids content (ssc, percentage of glucose plus fructose, in ${ }^{\circ}$ Brix) and $p H$ were measured from juice with a refractometer and a $\mathrm{pH}$ meter respectively. Titratable acidity ( $t a$, grams of citric acid per $100 \mathrm{~g}$ of juice), was calculated as the necessary volume of sodium hydroxide to turn the $\mathrm{pH}$ of a $10 \% \mathrm{~m} / \mathrm{m}$ homogenate juice to 8.1 .

\section{Genetic analysis}

Genomic DNA was extracted from young seedlings using the Wizard Genomic commercial kit (Promega, USA) following the manufacturer's protocol. InDel and CAPS molecular markers were used. The marker sequences and specific restriction endonucleases used are shown in Table 1. Electrophoresis of molecular markers TG176, TG45 and EP912/EP913 was conducted on $3 \% \mathrm{w} / \mathrm{v}$ agarose gels, while TG337 was run on a $1 \% \mathrm{w} / \mathrm{v}$ agarose gel. Gels were stained with ethidium bromide for visualization. PCR products for Lewus and EP170/EP171 were separated on $6 \% \mathrm{w} / \mathrm{v}$ polyacrilamyde gel and visualized by silver staining procedure.

\section{Statistical analysis}

The normal distribution of evaluated traits in the parental genotypes and the segregating population was verified by the Shapiro-Wilk test (Shapiro and Wilk 1965). The $t$ test (Snedecor 1964) or Kruskal-Wallis test (Kruskal and Wallis 1952) was applied for comparison of mean values in the parental genotypes. Pearson correlation coefficients were estimated among all traits.

In the segregating population, the broad sense heritability $\left(\mathrm{H}^{2}\right)$ of all traits was estimated through an ANOVA (Mariotti and Collavino 2014) and histograms of frequency were also performed.

The single point method (Tanksley 1993) was used to study the association between molecular markers and attributes. All these statistical analyses were carried out with InfoStat software Version 1.0 (Di Renzo et al. 2001). The d/a parameter of the additivedominant model was calculated for those traits in which significant association was detected with one or more molecular markers and when significant differences between homozygous genotypes mean values was detected (Tanksley 1993). If complete dominance was not detected, a confidence interval of $95 \%$ for the average of the heterozygous genotype was calculated. If the mid-point value was within the range of the interval of confidence, an additive gene action was assumed, otherwise partial dominance.

When both genomic region were associated with the same phenotypic trait, a digenic linear additive model was tested by a Chi square test (Snedecor 1964). The free software environment R (R Core Team 2014) was used to perform a regression analysis between the most significant markers and the associated attribute. Genotype mean value within each QTL were plotted in order to facilitate the data visualization. The average value $(\mathrm{m})$ and additive effect $\left(\mathrm{a}_{\mathrm{i}}\right)$ for a linear additive model were estimated for each trait. The expected phenotype values at different genotypes for a trait $\left(E_{p h}\right)$ were estimated based on a linear additive model that includes the additive effect (a) in each genomic regions $(f s 2.1$ and $f s 8.1)$ :

$\mathrm{E}_{\mathrm{ph}}=\mathrm{m}+\mathrm{a}_{\mathrm{fs} 2.1}+\mathrm{a}_{\mathrm{fs} 8.1}$

A two-way analysis of variance (ANOVA) was used to assess the existence of epistatic interactions between genomic regions. For this analysis, one molecular marker per region was chosen for having the higher $\mathrm{R}^{2}$ value for the trait. Orthogonal contrasts were applied to determine the type of genic interaction following the methodology proposed by Jana (1972).

Finally, a regression plot between the expected values and the observed phenotypic values was performed only for traits with significant epistatic effects. These statistical analyses were carried out with InfoStat software Version 1.0 (Di Renzo et al. 2001).

\section{Results and discussion}

Phenotypic analysis in the parental genotypes and the segregating population $\mathrm{F}_{3}-\mathrm{BC}_{1}-\mathrm{S}_{1}$

Rio Grande exhibited significant differences in morphology when compared with LA1589. Fruits from RG were classified as "heart-shape" by Rodríguez et al. (2011) and clustered with accessions that show rectangular fruit and does not show the cultivated 
alleles at SUN, OVATE, FAS and $L C$ genes. In contrast, fruits from the wild parental genotypes LA1589 are small (less than $1 \mathrm{~g}$ weight) and spherical.

Significant differences $(\mathrm{P}<0.05)$ between parents were found for each morphological trait and fruit quality traits except for $p H$ (Table 2). Mean values for ar, fs I, pblk20, tri20 and tip were higher in Rio Grande than in LA1589. These results can be explained by the size and shape of the cultivated fruit. Rio Grande has large elongated $\left(f_{s} I>1.00\right)$ fruits which are also blocky-shaped at the upper side and sometimes have a tip at the lower end (tip value $0.01 \pm 0.01$ ). Mean values from the wild parent were higher than the mean values from the cultivated parent for $t a, s s c$, and $a / b$.

Several studies (Rodríguez et al. 2006, 2010b, Pratta et al. 2011, Pereira da Costa et al. 2013) have reported that some wild accessions (e.g., LA722 of $S$. pimpinellifolium or LA1385 S. lycopersicum var. cerasiforme) have better phenotypic values for quality traits such as $s s c$ an $t a$ than cultivated genotypes (e.g., cv. Caimanta of S. lycopersicum). Also, Georgelis et al. (2006) have reported that the PI 270248 accession of $S$. lycopersicon var. cerasiforme has approximately $43 \%$ more of soluble solids than the 7833 accession of $S$. lycopersicum. All these reports demonstrated the superiority of the wild genotype for those traits compared with cultivated tomatoes. Rio Grande shows higher mean values for $s l, f$ and $L$ than LA1589 (Table 2). In contrast, other reports have shown that wild genotypes are usually more resistant to postharvest deterioration than cultivated genotypes (Rodríguez et al. 2006, 2010b, Pereira da Costa et al. 2013).

Phenotypic distributions for the evaluated traits in the segregating population are shown in the Fig. 1. Each distribution includes the mean value for both parental genotypes indicated by arrows. Most of traits showed normal distribution with exception for tip and $t a$. Some traits also showed transgressive segregation such as pblk20, dblk20, tri20, tip, sl, f, pH and ta

Table 2 Mean values of all analyzed traits in Rio Grande of S. lycopersicum and LA1589 of S. pimpinellifolium. Broad sense heritability values (in percentege) for all traits analyzed in the segregating population $\mathrm{F}_{3}-\mathrm{BC}_{1}-\mathrm{S}_{1}$

\begin{tabular}{|c|c|c|c|c|c|}
\hline \multirow[t]{2}{*}{ Category } & \multirow[t]{2}{*}{ Trait } & \multirow{2}{*}{$\begin{array}{l}\text { Rio Grande } \\
\text { Mean } \pm \text { SE }\end{array}$} & \multirow{2}{*}{$\begin{array}{l}\text { LA1589 } \\
\text { Mean } \pm \text { SE }\end{array}$} & \multicolumn{2}{|l|}{$\mathrm{F}_{3}-\mathrm{BC}_{1}-\mathrm{S}_{1}$} \\
\hline & & & & $\% \mathrm{H}^{2} \pm \mathrm{SE}$ & $P$ Value \\
\hline \multirow[t]{8}{*}{ Morphology } & $a r$ & $25.25 \pm 0.74^{\mathrm{a}}$ & $0.75 \pm 0.03^{b}$ & $87 \pm 2$ & $<0.0001$ \\
\hline & $f_{s} I$ & $1.35 \pm 0.02^{\mathrm{a}}$ & $1.01 \pm 0.02^{\mathrm{b}}$ & $73 \pm 3$ & $<0.0001$ \\
\hline & pblk20 & $0.68 \pm 0.04^{\mathrm{a}}$ & $0.63 \pm 0.01^{\mathrm{b}}$ & $47 \pm 3$ & $<0.0001$ \\
\hline & dblk20 & $0.55 \pm 0.04^{\mathrm{b}}$ & $0.59 \pm 0.00^{\mathrm{a}}$ & $54 \pm 3$ & $<0.0001$ \\
\hline & tri20 & $1.26 \pm 0.02^{\mathrm{a}}$ & $1.08 \pm 0.01^{\mathrm{b}}$ & $41 \pm 3$ & $<0.0001$ \\
\hline & pan 20 & $87.15 \pm 1.14^{b}$ & $110.54 \pm 2.77^{\mathrm{a}}$ & $68 \pm 3$ & $<0.0001$ \\
\hline & $\operatorname{dan} 20$ & $81.99 \pm 1.62^{\mathrm{b}}$ & $104.99 \pm 2.48^{\mathrm{a}}$ & $59 \pm 3$ & $<0.0001$ \\
\hline & tip & $0.01 \pm 0.01^{\mathrm{a}}$ & $0.00 \pm 0.00^{\mathrm{b}}$ & nc & \\
\hline \multirow[t]{8}{*}{ Quality } & $f w$ & $76.44 \pm 13.71^{\mathrm{a}}$ & $0.59 \pm 0.05^{\mathrm{b}}$ & $80 \pm 2$ & $<0.0001$ \\
\hline & $s l$ & $13.17 \pm 3.17^{\mathrm{a}}$ & $9.71 \pm 0.54^{\mathrm{b}}$ & $52 \pm 2$ & $<0.0001$ \\
\hline & $f$ & $61.51 \pm 3.24^{\mathrm{a}}$ & $50.88 \pm 1.03^{\mathrm{b}}$ & $58 \pm 3$ & $<0.0001$ \\
\hline & $L$ & $44.58 \pm 1.14^{\mathrm{a}}$ & $37.77 \pm 0.29^{b}$ & $53 \pm 3$ & $<0.0001$ \\
\hline & $a / b$ & $0.97 \pm 0.06^{\mathrm{b}}$ & $1.42 \pm 0.03^{\mathrm{a}}$ & $53 \pm 3$ & $<0.0001$ \\
\hline & $s s c$ & $4.67 \pm 0.22^{\mathrm{b}}$ & $14.57 \pm 3.07^{\mathrm{a}}$ & $92 \pm 3$ & $<0.0001$ \\
\hline & $p H$ & $4.71 \pm 0.22^{\mathrm{a}}$ & $4.75 \pm 0.04^{\mathrm{a}}$ & $77 \pm 6$ & $<0.0001$ \\
\hline & $t a$ & $0.35 \pm 0.09^{\mathrm{b}}$ & $1.00 \pm 0.27^{\mathrm{a}}$ & $\mathrm{nc}$ & \\
\hline
\end{tabular}

$S E$ standard error, $\% \mathrm{H}^{2}$ broad sense heritability in percentage, $P$-value probability of type I error $(\alpha)$, ar fruit area, $f_{S} I$ fruit shape index I, pblk20 proximal fruit end blockiness, $d b l k 20$ distal fruit end blockiness, tri2 0 fruit shape triangle, pan 20 proximal fruit end angle, dan 20 distal fruit end angle, tip distal fruit end protrusion, $f w$ fruit weigh, $s l$ fruit shelf life, $f$ firmness, $L$ color parameter, $a / b$ chroma index, ssc soluble solid content, ta titatrable acidity, nc not calculated. Different letters indicate significant differences $(\mathrm{P}<0.05)$ 
(Fig. 1). The presence of complementary alleles between parents could explain the transgressive segregation found in this population for these traits. Genetic variability for all traits was demonstrated through $\% \mathrm{H}^{2}$ values which were all highly significant (Table 2). The highest $\% \mathrm{H}^{2}$ values for fruit morphology attributes were found for $a r$ and $f_{s} I$ and for some fruit quality traits such as $f w$, ssc and $t a$. The $\% \mathrm{H}^{2}$ values for tip and $t a$ were not calculated because they do not adjust to a normal distribution.

Significant $(\mathrm{P}<0.05)$ phenotypic correlations were observed among morphological traits such as fsI, dblk20, tri20, pan20, dan20 and tip (Table S1). An expected positive correlation was observed between $a r$ and $f w(\mathrm{r}=0.92)$. On the other hand, negative correlation between color parameters $L$ and $a / b$ was observed and between fruit area and soluble solids content.

Detection of QTLs and gene action (d/a)

A total of 17 QTLs were detected by mean of single point analysis. Eleven QTLs were located on chromosome 2 and six on chromosome 8 (Table 3). Major QTLs (\% $\mathrm{R}^{2}$ higher than $20 \%$ ) for $f_{s} I$, dblk20, tri20 and tip were detected on chromosome 2 and for $f_{s} I$, pan20 and dan20 on chromosome 8. Minor QTLs (\% $\mathrm{R}^{2}$ lower than $20 \%$ ) for ar, pblk20, pan20, dan20, $p H, a / b$ and $L$ were found on chromosome 2 and three QTLs for $a r$, tip and $s l$ on chromosome 8. Partial or complete dominance of the wild alleles was generally observed for morphological traits and an additive gene action for quality traits (Table 3).

Although both assessed genomic regions were associated with distal fruit end traits, the $\% \mathrm{R}^{2}$ values of QTLs in $f s 2.1$ were higher than those QTLs in $f_{s} 8.1$. The distal part of chromosome 2 has stronger associations with tip and tri20 attributes, and the last attribute was significantly associated with molecular markers in $f$ s2.1 (Table 3). These results are consistent with those reported by Gonzalo and van der Knaap (2008) who found QTLs on chromosome 2 for tri20, dblk20 and dan20 in the $\mathrm{F}_{2}$ population derived from Rio Grande and LA1589 cross. On the other hand, fs8.1 seems control both proximal and distal morphological attributes because it has a highly significant effect on pan20 and dan20. Ku et al. (2000) concluded that the region containing $f_{s} 8.1$ affects fruit growth in the longitudinal dimension and in this work similar results were found.

Several minor QTLs were detected for fruit quality traits in this segregating population. A minor QTL on chromosome 8 , which had been associated with EP912/EP913 marker, explained $5.62 \%$ of the phenotypic variation observed for $s l(\mathrm{P}=0.03$; Table 3$)$. The presence of the wild alleles improved this trait. As it was mentioned before, complementary long shelf life alleles carried by the parental genotypes could explain the transgressive segregation found in this population for this trait (Fig. 1). The presence of a QTL for fruit shelf life on chromosome 8 was also reported by Pereira da Costa et al. (2013) and explained the $18 \%$ of the phenotypic variability observed in $\mathrm{BC}_{1}-\mathrm{S}_{1}$ families derived from the cross between Caimanta and LA722 of S. pimpinellifolium.

Another minor QTL for $p H$ was detected on chromosome 2 (EP170/EP171 marker) and explained the $6.45 \%$ of the observed phenotypic variance (Table 3). The d/a parameter could not be calculated for this trait because no difference was observed between homozygous mean values. Despite this fact, overdominance (mean value for the heterozygous genotype is higher than for both homozygous ones) can be seen for this trait in Table 3. This result agrees with that reported by Bernacchi et al. (1998), who detected a minor QTL on chromosome 2 that explained the $10 \%$ of the phenotypic variability for $p H$ in advanced backcross between $S$. habrochaites and $S$. lycopersicum. However, in that study the presence of $S$. habrochaites alleles reduces the mean value of the trait. Under the hypothesis that the same QTL for $p H$ was detected at both studies, the differential behavior of wild alleles over the trait could be explained by allelic differences (S. pimpinellifolium or S.habrochaites) and their interactions with the respective genetic background.

Minor QTLs for color parameters L $\left(\mathrm{R}^{2}=11.36 \%\right)$ and $\mathrm{a} / \mathrm{b}\left(\mathrm{R}^{2}=7.61 \%\right)$ were detected on chromosome 2 associated with EP170/EP171 marker. An additive gene action was observed for these traits through the $\mathrm{d} / \mathrm{a}$ parameter (Table 3 ).

The FW2.2 gene on chromosome 2 that controls fruit weight was the first identified by positional mapping in tomato (Frary et al. 2000). Nesbitt and Tanksley (2002) after evaluating and comparing the coding sequences and gene promoters of different 

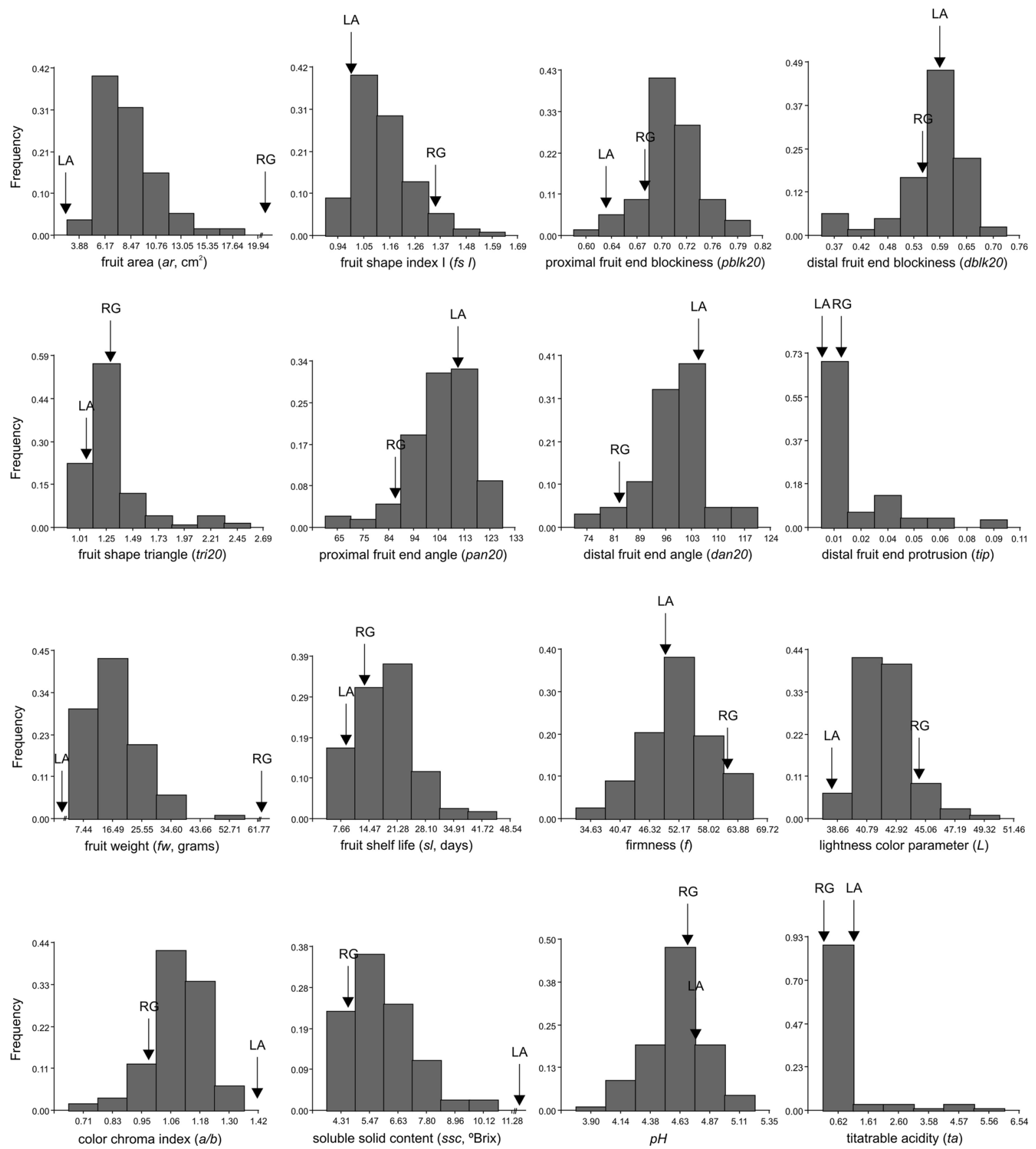

Fig. 1 Phenotypic distributions for fruit area (area, in $\mathrm{cm}^{2}$ ), fruit shape index I $\left(f_{s} I\right)$, proximal fruit end blockiness ( $\left.p b l k 20\right)$, distal fruit end blockiness (dblk20), fruit shape triangle (tri20), proximal fruit end angle (pan20, in ${ }^{\circ}$ ), distal fruit end angle $\left(\right.$ dan 20 , in $\left.{ }^{\circ}\right)$, distal fruit end protrusion (tip), fruit weight ( $f w$, in

g), fruit shelf life ( $s l$, in days), firmness $(f)$, lightness color parameter $(L)$, color chroma index $(a / b)$, soluble solid content ( $s s c$, in ${ }^{\circ} \mathrm{Brix}$ ), $\mathrm{pH}$, and titratable acidity ( $t a$, in $\mathrm{g}$ of citric acid per $100 \mathrm{~g}$ of tomato juice) in the segregating population $\mathrm{F}_{3}-\mathrm{BC}_{1}-\mathrm{S}_{1}$

accessions of $S$. lycopersicon, S. lycopersicon var. cerasiforme and $S$. pimpinellifolium, concluded that $F W 2.2$ should be present in every cultivated tomato. In

spite of the great difference among parents for fruit weight, the high genetic variability detected for this attribute in the analyzed segregating population and 
Table 3 QTL analysis in the segregating population $\mathrm{F}_{3}-\mathrm{BC}_{1}-\mathrm{S}_{1}$ for morphological and fruit quality traits

\begin{tabular}{|c|c|c|c|c|c|c|c|c|c|c|c|c|}
\hline Category & Trait & Most significant marker & Chr. & P-value & $\% \mathrm{R}^{2}$ & $\mathrm{~N}$ & LL & $\mathrm{n}$ & LP & $\mathrm{n}$ & PP & $\mathrm{d} / \mathrm{a}$ \\
\hline \multirow[t]{13}{*}{ Morphology } & \multirow[t]{2}{*}{$a r$} & EP170/EP171 & 2 & 0.01 & 6.80 & 40 & $9.14^{\mathrm{a}}$ & 55 & $7.79^{\mathrm{b}}$ & 29 & $7.44^{\mathrm{b}}$ & cd. PP \\
\hline & & TG176 & 8 & 0.02 & 6.51 & 20 & $9.49^{\mathrm{a}}$ & 59 & $8.18^{\mathrm{ab}}$ & 44 & $7.44^{\mathrm{b}}$ & $\mathrm{ad}$ \\
\hline & \multirow[t]{2}{*}{$f_{s} I$} & TG337 & 2 & $<0.0001$ & 29.69 & 44 & $1.22^{\mathrm{a}}$ & 52 & $1.09^{\mathrm{b}}$ & 28 & $1.06^{\mathrm{b}}$ & cd. PP \\
\hline & & TG45 & 8 & $<0.0001$ & 30.34 & 22 & $1.27^{\mathrm{a}}$ & 61 & $1.13^{\mathrm{b}}$ & 40 & $1.06^{\mathrm{c}}$ & pd. PP \\
\hline & pblk20 & EP170/EP171 & 2 & 0.03 & 5.83 & 40 & $0.72^{\mathrm{a}}$ & 55 & $0.71^{\mathrm{ab}}$ & 29 & $0.70^{\mathrm{b}}$ & $\mathrm{ad}$ \\
\hline & dblk20 & EP170/EP171 & 2 & $<0.0001$ & 46.03 & 40 & $0.50^{\mathrm{b}}$ & 55 & $0.60^{\mathrm{a}}$ & 29 & $0.61^{\mathrm{a}}$ & cd. PP \\
\hline & tri20 & EP170/EP171 & 2 & $<0.0001$ & 47.89 & 40 & $1.58^{\mathrm{a}}$ & 55 & $1.19^{\mathrm{b}}$ & 29 & $1.15^{\mathrm{b}}$ & cd. PP \\
\hline & \multirow[t]{2}{*}{$\operatorname{pan} 20$} & TG337 & 2 & $<0.0001$ & 15.49 & 44 & $98.17^{\mathrm{b}}$ & 52 & $107.92^{\mathrm{a}}$ & 28 & $108.16^{\mathrm{a}}$ & cd. PP \\
\hline & & TG45 & 8 & $<0.0001$ & 32.82 & 22 & $90.49^{c}$ & 61 & $104.76^{\mathrm{b}}$ & 40 & $110.88^{\mathrm{a}}$ & pd. PP \\
\hline & \multirow[t]{2}{*}{ dan 20} & TG337 & 2 & $<0.005$ & 10.00 & 44 & $94.41^{\mathrm{b}}$ & 52 & $99.87^{\mathrm{a}}$ & 28 & $100.56^{\mathrm{a}}$ & cd. PP \\
\hline & & TG45 & 8 & $<0.0001$ & 31.74 & 22 & $87.85^{\mathrm{c}}$ & 61 & $98.65^{\mathrm{b}}$ & 40 & $102.21^{\mathrm{a}}$ & pd. PP \\
\hline & \multirow[t]{2}{*}{ tip } & TG337 & 2 & $<0.0001$ & 38.19 & 44 & $0.03^{\mathrm{a}}$ & 52 & $0.01^{\mathrm{b}}$ & 28 & $0.00^{\mathrm{b}}$ & cd. PP \\
\hline & & TG45 & 8 & $<0.001$ & 15.82 & 22 & $0.02^{\mathrm{a}}$ & 61 & $0.02^{\mathrm{a}}$ & 40 & $0.01^{\mathrm{b}}$ & cd. LL \\
\hline \multirow[t]{4}{*}{ Quality } & $s l$ & EP912/EP913 & 8 & 0.03 & 5.62 & 23 & $15.07^{\mathrm{b}}$ & 63 & $18.42^{\mathrm{ab}}$ & 35 & $20.20^{\mathrm{a}}$ & $\mathrm{ad}$ \\
\hline & $p H$ & EP170/EP171 & 2 & 0.03 & 6.45 & 34 & $4.54^{\mathrm{b}}$ & 50 & $4.65^{\mathrm{a}}$ & 28 & $4.53^{\mathrm{b}}$ & $\mathrm{nc}$ \\
\hline & $L$ & EP170/EP171 & 2 & $<0.001$ & 11.36 & 40 & $42.84^{\mathrm{a}}$ & 52 & $41.98^{b}$ & 28 & $41.11^{\mathrm{c}}$ & ad \\
\hline & $a / b$ & EP170/EP171 & 2 & 0.01 & 7.61 & 40 & $1.06^{\mathrm{b}}$ & 52 & $1.10^{\mathrm{ab}}$ & 28 & $1.15^{\mathrm{a}}$ & $\mathrm{ad}$ \\
\hline
\end{tabular}

Chr. chromosome, $P$-value probability of type I error $(\alpha), \% \mathrm{R}^{2}$ percentage of the phenotypic variability explained by the locus, $L L$ homozygous for Rio Grande alleles, $L P$ heterozygous, $P P$ homozygous for LA1589 alleles, ar fruit area, $f s I$ fruit shape index I, pblk20 proximal fruit end blockiness, dblk20 distal fruit end blockiness, tri20 fruit shape triangle, pan20 proximal fruit end angle, dan20 distal fruit end angle, tip distal fruit end protrusion, $s l$ fruit shelf life, $L$ color parameter, $a / b$ chroma index, nc not calculated, ad additivity, cd complete dominance, pd partial dominance. Different letters indicate significant differences $(\mathrm{P}<0.05)$ according to a $t$-test

having a molecular marker (EP170/EP171) positioned on this gene ( $F W 2.2)$, none QTL was identified for $f w$ in the analyzed genomic region. The lack of association found in this report could be due to fixation of wild alleles at loci controlling the trait in the genetic background under study. This statement is based on previous reports that the region containing $F W 2.2$ has a high recombination rate (Grandillo and Tanksley 1996; Lippman and Tanksley 2001). Hence, this fact indicates that other genomic regions uncovered in this experiment underlie $f w$ variation in the assayed segregating population.

Digenic linear additive model and epistasis

The highest $\% \mathrm{R}^{2}$ values were found for $a r, f_{s} I$, pan 20 , dan 20 and tip (Table 3). These attributes were associated with almost all molecular markers at both studied genomics regions therefore were used to test a linear additive model and epistatic interactions. Only one molecular marker per region and trait (those with highest $\% \mathrm{R}^{2}$ in the one-way ANOVA) were selected to test the additive linear model and epistasis. The phenotypic values at those markers were used to estimate the $m$ and $a_{i}$ coefficients of the digenic linear additive model (Fig. A1 in supplementary material). Fruit area, $f_{S} I$ and dan20 adjusted to the proposed model $\left(\chi^{2}<15.5, \mathrm{P}>0.05\right)$ whereas pan20 and tip $\operatorname{did} \operatorname{not}\left(\chi^{2}>15.51, \mathrm{P}<0.05\right)$.

Epistasis or interaction between loci were significant $(\mathrm{P}<0.05)$ for $f s I$, pan20 and tip (Table 4). Mean values for each genotype at $f_{s} 2.1$ were plotted in the $\mathrm{x}$-axis against different genotypes at $f_{s} 8.1$ in the $\mathrm{y}$-axis (Fig. 2).

Epistasis occurs when differences in genotypic values at one locus vary depending on the genotype present at a second locus (Cheverud and Routman 1995). Using a two-way ANOVA and orthogonal contrast, it was found that additive gene actions were highly significant $(\mathrm{P}<0.0001)$ at both loci and dominant gene action at $f s 2.1$ was slightly significant $(\mathrm{P}=0.03$; Table 5). Additive-by-additive epistatic 
Table 4 Two-way ANOVA results for fruit shape index, proximal fruit end angle macro and distal fruit end protrusion

\begin{tabular}{llccc}
\hline Trait & Molecular marker & F-value & P-value & $\% \mathrm{R}^{2}$ \\
\hline$f_{S} I$ & TG337 & 36.76 & $<0.0001$ & 29.69 \\
& TG45 & 28.62 & $<0.0001$ & 30.34 \\
& TG337 $\times$ TG45 & 3.27 & 0.01 & 61.55 \\
pan20 & TG337 & 12.17 & $<0.0001$ & 15.49 \\
& TG45 & 24.91 & $<0.0001$ & 32.82 \\
& TG337 $\times$ TG45 & 3.26 & 0.01 & 46.63 \\
& TG337 & 37.70 & $<0.0001$ & 38.19 \\
& TG45 & 10.95 & $<0.001$ & 15.82 \\
& TG337 $\times$ TG45 & 4.04 & $<0.005$ & 45.70 \\
\hline
\end{tabular}

$P$-value probability of type I error $(\alpha), \% \mathrm{R}^{2}$ percentage of the phenotypic variability explained by the locus, $f s I$ fruit shape index I, pan 20 proximal fruit end angle, tip distal fruit end protrusion, TG337 molecular marker on chromosome 2, TG45 molecular marker on chromosome 8, TG337*TG45, interaction between chromosomes

interaction between $f s 2.1$ and $f s 8.1$ was significant for fs $I(\mathrm{P}<0.001$; Table 5). The significant individual effect and the interaction can be also visualized in Fig. 2.

An additive gene action was highly significant for pan20 in both loci $(\mathrm{P}<0.0001)$ and additive-byadditive epistasis was detected using orthogonal contrasts $(\mathrm{P}=0.02$; Table 5). However, dominant gene action in $f s 2.1(\mathrm{P}=0.03)$ and dominant-byadditive epistasis were also significant $(P=0.01$; Table 5) for this trait. This result agrees with those obtained for pan 20 by the $\mathrm{d} / \mathrm{a}$ parameter where complete dominance of wild alleles was observed in fs2.1 (Table 3).

For tip, two major QTLs were detected on chromosomes 2 and 8 and the presence of cultivated alleles led to an increase in the average mean value of this trait (Table 3). An additive gene action was highly significant at both loci $(\mathrm{P}<0.001)$ as the dominant effect in $f s 2.1 \quad(\mathrm{P}<0.005$; Table 5). This result is consistent with those obtained for this trait by $\mathrm{d} / \mathrm{a}$ parameter, where complete dominance of wild alleles was observed in $f s 2.1$ region (Table 3 ). Dominant-byadditive epistasis was observed between these loci using orthogonal contrasts $(\mathrm{P}<0.005$; Table 5$)$.

Regression plots for traits with significant epistatic effects ( $f$ I, pan20, and tip) are shown in Fig. 3. The dashed line in each graph represents the linear additive model for both genomic regions ( $f_{s} 2.1$ and $\left.f_{s} 8.1\right)$. The
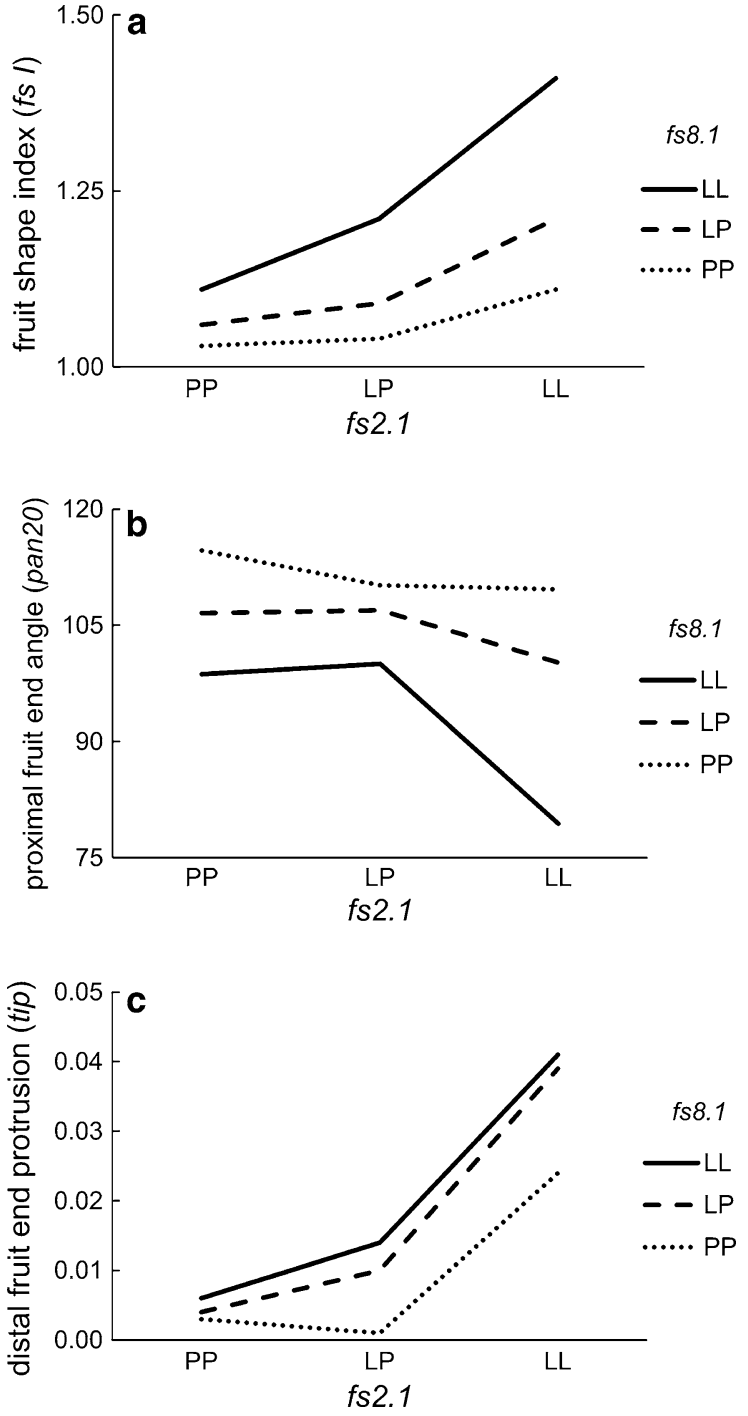

Fig. 2 Effects of interactions on fruit shape index I ( $f s I)$, proximal fruit end angle (pan20) and distal fruit end protrusion (tip) between the loci marked by TG337 ( $f$ s2.1) and TG45 $(f s 8.1)$. The vertical axis represents a fruit shape index $\left(f_{s} I\right)$, b proximal fruit end angle (pan20, in ${ }^{\circ}$ ) and $\mathbf{c}$ distal fruit end protrusion (tip). LL, LP and PP represents the three genotypes of each locus: $L L$ homozygous for Rio Grande alleles, $L P$ heterozygous, $P P$ homozygous for LA1589 alleles

$f_{s} I$ trait adjusts to a digenic linear model which agrees with the two-way ANOVA results, i.e., the observed phenotype for the trait is explained by the individual additive effect of each locus and an additive-additive interaction. For pan 20 the genotypes PP_PP, LP_LL, LL_LP and LP_LP were the most divergent from the linear additive model. These results agree with those obtained in the two-way ANOVA (Table 4) and the 
Table 5 Orthogonal contrast for fruit shape index, proximal fruit end angle macro and distal fruit end protrusion

$P$-value probability of type I error $(\alpha), f_{s} I$ fruit shape index I, pan 20 proximal fruit end angle, tip distal fruit end protrusion

\begin{tabular}{lccc}
\hline Interaction & $\begin{array}{c}f_{s} I \\
\text { P-value }\end{array}$ & $\begin{array}{c}\text { pan20 } \\
\text { P-value }\end{array}$ & $\begin{array}{l}\text { tip } \\
\text { P-value }\end{array}$ \\
\hline Additive $f_{s} 2.1$ & $<0.0001$ & $<0.0001$ & $<0.0001$ \\
Additive $f_{s} 8.1$ & $<0.0001$ & $<0.0001$ & $<0.001$ \\
Dominant $f_{s} 2.1$ & 0.03 & 0.01 & $<0.005$ \\
Dominant $f s 8.1$ & 0.05 & 0.06 & 0.04 \\
Additive $f_{s} 2.1$-by- additive $f_{s} 8.1$ & $<0.001$ & 0.02 & 0.79 \\
Additive $f_{s} 2.1$-by- dominant $f_{s} 8.1$ & 0.40 & 0.53 & 0.21 \\
Dominant $f s 2.1$-by- additive $f_{s} 8.1$ & 0.62 & 0.03 & $<0.005$ \\
Dominant $f s 2.1$-by- dominant $f_{s} 8.1$ & 0.90 & 0.63 & 0.07 \\
\hline
\end{tabular}

orthogonal contrast for pan20 (Table 5). For tip, genotypes carrying the heterozygous alleles at $f_{s} 2.1$ (LP_PP, LP_LP and LP_LL) were the most divergent from the additive model followed for the genotypes carrying the cultivated homozygous alleles on $f_{s} 2.1$ (LL_PP, LL_LP and LL_LL). An additive gene action was highly significant $(\mathrm{P}<0.001)$ at both loci, a dominant effect in $f s 2.1$ was also significant $(\mathrm{P}<0.005)$ and a dominant-by-additive epistasis was observed between these loci $(\mathrm{P}<0.005)$. Summarizing, all deviations between the observed versus the expected values for each trait agrees with the twoway ANOVA (Table 4) and the orthogonal contrast results (Table 5).

According to the results of the two-way ANOVA, $f s 2.1$ and $f s 8.1$ together accounted for $61.55,46.63$ and $45.70 \%$ of the phenotypic variability for $f_{s} I$, pan 20 and tip respectively (Table 4 ). If we want to know the percentage of genetic variability that can be explained by $f s 2.1$ and $f_{s} 8.1$ for the $f_{s} I$ trait we only have to do the rate between the $\% \mathrm{R}^{2}$ value (Table 4 ) and the $\% \mathrm{H}^{2}$ value (Table 2). Thus, the $84.31,68.57$ and $84.63 \%$ of the genetic variability for $f s I$, pan20 and tip respectively can be explained by these two QTLs ( $f s 2.1$ and $f s 8.1)$.

In Fig. 4 discrepancies in fruit morphology can be visualized when different combinations of homozygous genotypes at $f s 2.1$ and $f s 8.1$ are present. Rounded morphology is recovered when wild alleles are present at homozygous state at both loci $(f s 2.1$ and $f s 8.1)$. The presence of cultivated alleles at only one locus ( $f s 2.1$ or $f_{s 8.1)}$ generate an intermediate morphology with an $f_{s} I$ mean value similar to that obtain for a double heterozygous plant (LP at $f s 2.1$ and LP at $f s 8.1$, Fig. 2a). Finally, the most elongated fruit shape can be seen when cultivated alleles are present at homozygous state at both loci. In conclusion, these two loci have a synergistic effect over fruit shape index. The presence of wild alleles leads to an increase in pan 20. Due to the highest \% $\mathrm{R}^{2}$ of $f_{s} 8.1$ respect of $f_{s} 2.1$, the change of wild alleles for cultivated alleles at $f s 2.1$ do not generate a great change in the mean value of that trait (Fig. 4). In contrast, the presence of cultivated alleles at $f s 8.1$ generates a significant reduction in the mean value of pan20, being greater when cultivated alleles at homozygous state are present at both loci. A similar behavior can be seen for tip, but in this case the presence of cultivated alleles leads to an increase in the trait. At Fig. 4 we can see that this morphological trait is visible only when cultivated alleles are present at $f s 2.1$, regardless of the genotype at $f s 8.1$. This could be explained because of the differences at the $\% \mathrm{R}^{2}$ values, $f s 2.1$ explain more than twice of the phenotypic variance for the trait than $f_{s} 8.1$ in this population.

Other studies revealed that epistasis may control a significant part of the genetic variation for quantitative traits in tomato. For example, Causse et al. (2007) when evaluating introgressed-lines derived from the cross between Cervil of $S$. lycopersicum var. cerasiforme and Levovil of S. lycopersicum found epistatic effects for fruit weight, locule number, firmness, soluble solids content, sugar content and titratable acidity. Lippman and Tanksley (2001) also detected a highly significant interaction between two QTLs lcn2.1 and lcn11.1 that control locule number. 
Fig. 3 Regression plots of expected versus observed phenotypic values for traits with significant epistatic effects. a Fruit shape index I ( $f s I$ ). b Proximal fruit end angle (pan20). c Distal fruit end protrusion (tip). The dashed lines represent the expected values for the digenic linear additive model. Genotypes: $L L$ homozygous for Rio Grande alleles, $L P$ heterozygous, $P P$ homozygous for LA1589 alleles. LL_LL, LL_LP, LL_PP, LP_LL, LP_LP, LP_PP, PP_LL, PP_LP and PP_PP represent all the different combinations for both loci. The first two letters indicates the genotype of the region $f_{s} 2.1$ and the last two the genotype of the region $f_{s} 8.1$
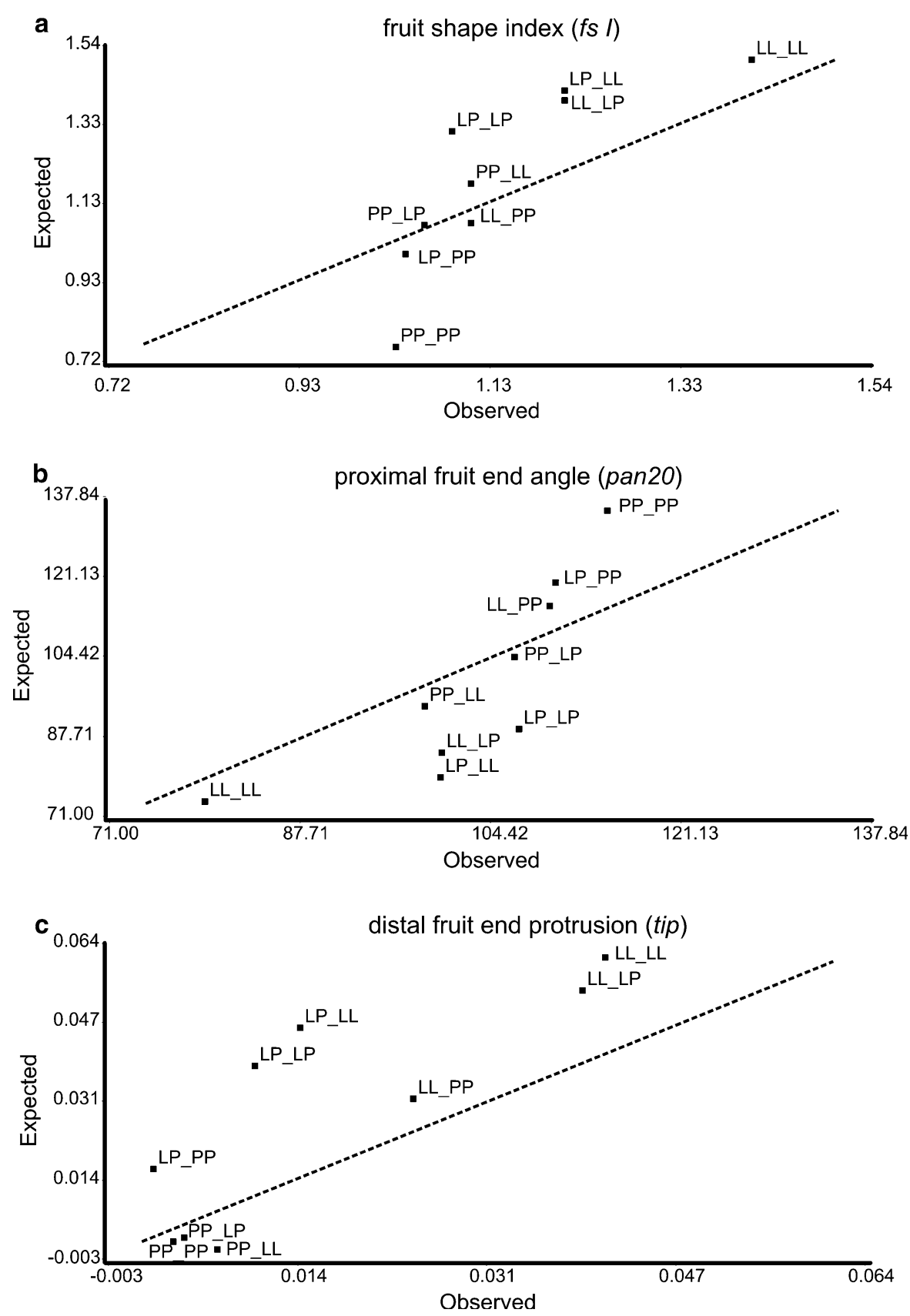

Those results were obtained using an $\mathrm{F}_{2}$ population derived from the cross between LA1589 of $S$. pimpinellifolium and Giant Heirloom of S. lycopersicum. The authors observed a disproportional increase in locule number when both loci were homozygous for Giant Heirloom alleles.

\section{Conclusions}

The individual effects of $f s 2.1$ and $f_{s} 8.1$ on fruit morphological traits were validated in a different segregating population derived from the cross between cv. Rio Grande of S. lycopersicum and LA1589 of $S$. 


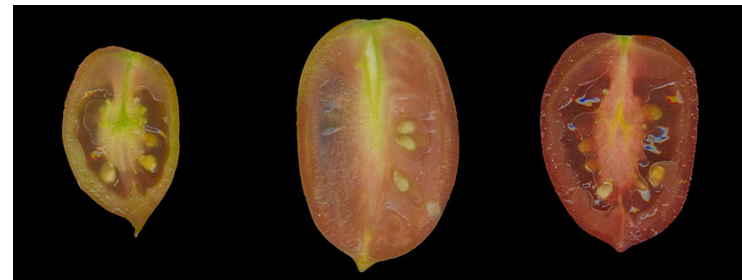

fs2.1: LL - fs8.1: LL

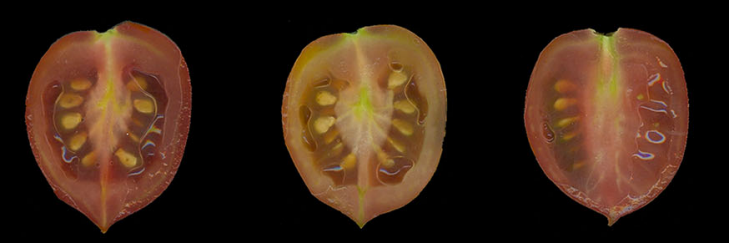

fs2.1: LL - fs8.1: PP

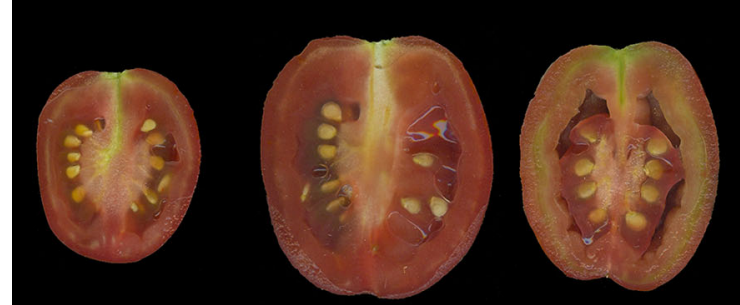

fs2.1: PP - fs8.1: LL

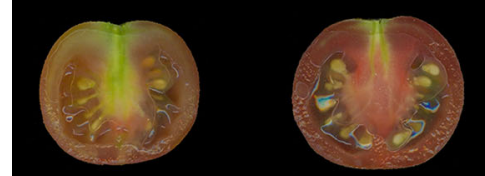

$f_{s} 2.1: P P-f s 8.1: P P$

$1 \mathrm{~cm}$

Fig. 4 Fruits from three representative plant for the combination of loci $f_{s} 2.1$ and $f_{s} 8.1$ at homozygous state in the segregating population $\mathrm{F}_{3}-\mathrm{BC}_{1}-\mathrm{S}_{1}$. LL indicates the presence of cultivated alleles (Rio Grande) while PP indicates the presence of wild alleles (LA1589)

pimpinellifolium. Some reported QTLs for fruit quality traits such as $L, a / b, p H$ and $s l$ in distant tomato crosses were also confirmed in this segregating population. Further experiments should be done to define if QTLs of morphological traits have pleiotropic effect on fruit quality or they are different tightened linked loci. $f_{s} 2.1$ and $f_{s} 8.1$ do not share the control on the same fruit quality traits. On the other hand, these genomic regions control ar, fs I and dan 20 according to a digenic linear model and also interact in an epistatic way for $f_{S} I$, pan 20 and tip traits to define the fruit morphology. The homozygous state at both loci ( $f_{s 2} .1$ and $\left.f_{s 8.1}\right)$ allows recover parental phenotypes whereas all other possible combinations interact to generate semi-elongated fruits.

\section{References}

Bernacchi D, Beck-Bunn T, Eshed Y et al (1998) Advanced backcross QTL analysis in tomato. I. Identification of QTLs for traits of agronomic importance from Lycopersicon hirsutum. Theor Appl Genet 97:381-397. doi:10.1007/ s001220050908

Buescher RW, Sistrunk WA, Tigchelaar EC, Ng TJ (1976) Softening, pectolytic activity, and storage-life of rin and nor tomato hybrids. HortScience 11:603-604

Causse M, Chaib J, Lecomte L et al (2007) Both additivity and epistasis control the genetic variation for fruit quality traits in tomato. Theor Appl Genet 115:429-442. doi:10.1007/ s00122-007-0578-1

Cheverud JM, Routman EJ (1995) Epistasis and its contributions to genetic variance components. Genetics 139:1455-1461

Di Renzo JA, Casanoves F, Balzarini MG, Gonzalez L, Tablada M, Robledo CW (2001) Infostat, versión 2001, Grupo Infostat, FCA. Universidad Nacional de Córdoba, Argentina

Frary A, Nesbitt TC, Frary A et al (2000) fw2.2: a quantitative trait locus key to the evolution of tomato fruit size. Science 289:85-88. doi:10.1126/science.289.5476.85

Georgelis N, Scott JW, Baldwin EA (2006) Inheritance of high sugars from tomato accession PI 270248 and environmental variation between seasons. J Am Soc Hortic Sci 131:41-45

Gonzalo MJ, van der Knaap E (2008) A comparative analysis into the genetic bases of morphology in tomato varieties exhibiting elongated fruit shape. Theor Appl Genet 116:647-656. doi:10.1007/s00122-007-0698-7

Grandillo S, Tanksley SD (1996) QTL analysis of horticultural traits differentiating the cultivated tomato from the closely related species Lycopersicon pimpinellifolium. Theor Appl Genet 92:935-951. doi:10.1007/BF00224033

Grandillo S, Ku HM, Tanksley SD (1999) Identifying the loci responsible for natural variation in fruit size and shape in tomato. Theor Appl Genet 99:978-987. doi:10.1007/ s001220051405

Jana S (1972) Simulation of quantitative characters from qualitatively acting genes. Theor Appl Genet 42:119-124

Kruskal WH, Wallis WA (1952) Use of ranks in one-criterion variance analysis. J Am Stat Assoc 47:583-621

Ku HM, Grandillo S, Tanksley SD (2000) fs8.1, a major QTL, sets the pattern of tomato carpel shape well before anthesis. Theor Appl Genet 101:873-878

Lippman ZB, Tanksley SD (2001) Dissecting the genetic pathway to extreme fruit size in tomato using a cross between the small-fruited wild species Lycopersicon pimpinellifolium and L. esculentum var. Giant Heirloom. Genetics 158:413-422

Liu J, Van Eck J, Cong B, Tanksley SD (2002) A new class of regulatory genes underlying the cause of pear-shaped 
tomato fruit. Proc Natl Acad Sci U S A 99:13302-13306. doi:10.1073/pnas.162485999

Mariotti JA, Collavino NG (2014) Los caracteres cuantitativos en la mejora genética de los cultivos. Orientación Gráfica Editora, Buenos Aires

Nesbitt TC, Tanksley SD (2002) Comparative sequencing in the genus Lycopersicon : implications for the evolution of fruit size in the domestication of cultivated tomatoes. Genetics 162:365-379

Pereira da Costa JH, Rodríguez GR, Pratta GR et al (2013) QTL detection for fruit shelf life and quality traits across segregating populations of tomato. Sci Hortic 156:47-53

Pratta GR, Rodríguez GR, Zorzoli R et al (2011) Phenotypic and molecular characterization of selected tomato recombinant inbred lines derived from the cross Solanum lycopersicum $\times$ S. pimpinellifolium. J Genet 90:229-237

R Core Team (2014) R: a language and environment for statistical computing. R Foundation for Statistical Computing, Vienna. http://www.R-project.org/

Rodríguez GR, Pratta GR, Zorzoli R, Picardi LA (2006) Evaluación de caracteres de planta y fruto en líneas recombinantes autofecundadas de tomate obtenidas por cruzamiento entre Lycopersicon esculentum y $L$. pimpinellifolium. Ciencia e Investigación Agraria 33:133-141

Rodríguez GR, Pratta GR, Liberatti DR et al (2010a) Inheritance of shelf life and other quality traits of tomato fruit estimated from F1's, F2's and backcross generations derived from standard cultivar, nor homozygote and wild cherry tomato. Euphytica 176:137-147. doi:10.1007/s10681-010-0241-9

Rodríguez GR, Strecker J, Brewer M, et al (2010b) Tomato analyzer user manual version 3
Rodríguez GR, Muños S, Anderson C et al (2011) Distribution of SUN, OVATE, LC, and FAS in the tomato germplasm and the relationship to fruit shape diversity. Plant Physiol 156:275-285. doi:10.1104/pp.110.167577

Saliba-Colombani V, Causse M, Langlois D et al (2001) Genetic analysis of organoleptic quality in fresh market tomato. 1. Mapping QTLs for physical and chemical traits. Theor Appl Genet 102:259-272. doi:10.1007/s001220051643

Schuelter AR, Finger FL, Casali VWD et al (2002) Inheritance and genetic linkage analysis of a firm-ripening tomato mutant. Plant Breed 121:338-342

Shapiro S, Wilk M (1965) An analysis of variance test for normality (complete samples). Biometrika 52:591-611

Simonne AH, Bridget BK, Marshall MM (2006) Consumers prefer low-priced and high-lycopene-content fresh-market tomatoes. HortTechnology 16:674-681

Snedecor G (1964) Métodos Estadísticos, 5ta edn. Compañía Editorial, México

Sun L, Rodriguez GR, Clevenger JP et al (2015) Candidate gene selection and detailed morphological evaluations of fs8.1, a quantitative trait locus controlling tomato fruit shape. J Exp Bot. doi:10.1093/jxb/erv361

Tanksley SD (1993) Mapping polygenes. Annu Rev Genet 27:205-233. doi:10.1146/annurev.ge.27.120193.001225

Tanksley SD (2004) The genetic, developmental, and molecular bases of fruit size and shape variation in tomato. Plant Cell 16:181-189. doi:10.1105/tpc.018119.S182

Xiao H, Jiang N, Schaffner E et al (2008) A retrotransposonmediated gene duplication underlies morphological variation of tomato fruit. Science 319:1527-1530. doi:10.1126/ science. 1153040 